\title{
The Incidence of Retinal Detachment After Cataract Surgery ${ }^{\S}$
}

\author{
Thomas Olsen ${ }^{*}$ and Peter Jeppesen
}

Dept. of Ophthalmology, Aarhus University Hospital, Denmark

\begin{abstract}
Purpose: To estimate the cumulative risk of retinal detachment (RD) after routine cataract surgery by phacoemulsification.

Setting: Department of Ophthalmology, Aarhus University Hospital, Denmark

Methods: Retrospective cohort study based on 12.222 consecutive cataract surgeries in 7.856 patients using phacoemulsification over a 6 year period from 2000 to 2005. Cases with a diagnosis of RD were identified through the procedure-coding database at the Medical Registry of Aarhus University Hospital, which is based on Diagnosis Related Groups (DRG) and used to report to the Danish Patients Registry (LPR). For each case the age of the patient, gender, axial length, surgical complications, postoperative Nd:YAG capsulotomy and time interval between cataract surgery and RD were recorded.
\end{abstract}

Results: The mean follow-up time was 64.8 months (range 26.2-97.6 months). Forty-eight (48) cases of RD were identified making an overall cumulative risk of $0.39 \%$. As compared to the normal incidence of RD reported in the Scandinavian literature, the relative risk of RD following cataract surgery was about 2.3 times that of the natural incidence. As compared to the average cataract group, the group of RD following cataract surgery was characterized by a younger mean age (60.5 vs. 73.7 years), male gender (58.3\% vs 34.8\%), longer axial lengths (24.56 vs $23.25 \mathrm{~mm})$ and a higher frequency of surgical complications $(10.4 \%$ vs $1.8 \%)(\mathrm{p}<0.001)$ but not a higher frequency of $\mathrm{Nd}: \mathrm{YAG}$ capsulotomy $(\mathrm{p}>0.05)$,

Conclusions: The cumulative risk of RD after lens surgery was about 2.3 times the natural incidence but seems to be lower than that of older reports.

Synopsis: Retinal detachment following cataract surgery is associated with young age, male gender, long axial lengths and surgical complications. The cumulative risk of RD after lens surgery was about 2.3 times the natural.

Keywords: Cataract surgery, retinal detachment, complications, outcome, biometry.

\section{INTRODUCTION}

Retinal detachment (RD) is a well-known and serious complication following lens surgery. The estimates of the post-surgical incidence of RD vary greatly in the literature ranging from $0.2 \%$ to $3.6 \%[1-4]$, depending on follow-up time and the patient demographics. The risk is generally considered higher in younger myopic patients [5-11], following intracapsular surgery $[1,12,13]$ and in patients with capsular tear or vitreous loss during surgery $[1,6,7,14-$ 16]. The risk may be higher after Nd:YAG capsulotomy according to some reports $[9,10,15]$, but not in others $[14$, $16,17]$.

Because modern small-incision phacosurgery is generally believed to be less traumatic and to have a lower complication rate than the older techniques, some of the previously reported incidence may not be applicable to modern technique. Moreover, with the increasing use of lens surgery also in younger patients, it is important to know the risk in a contemporary clinical environment. This study was

*Address correspondence to this author at the University Eye Clinic, Aarhus Hospital NBG, DK-8000, Aarhus C, Denmark; Tel: +45 7846 3249, Fax: +45 7846 3230; E-mail: tkolsen@dadlnet.dk

${ }^{\S}$ Presented at ASCRS 2009, San Francisco, April 2009. undertaken to evaluate the long-term cumulative risk of retinal detachment $(\mathrm{RD})$ following routine cataract surgery.

\section{MATERIAL AND METHODS}

Based on our electronic case record system we extracted a consecutive list of all adult cataract surgeries performed from year 2000 to 2005 . This material consisted of 12.222 consecutive cataract surgeries in 7.856 patients in the age range $20-101$ years, mean 73.7 years, and a median of 76.0 years. The standard surgical technique was phacoemulsification through a small incision $(2.6-2.8 \mathrm{~mm})$ with the implantation of an intraocular lens (IOL). In $94 \%$ of the cases the IOL was a foldable hydrophobic acrylic IOL (Alcon Acrysof) whereas in $6 \%$ of the cases it was a onepiece PMMA type of IOL (AMO CeeOn $812 \mathrm{C}$ or similar types). An anterior chamber IOL (Pharmacia 351C) was implanted in $0.2 \%$ of the cases.

Cases with a diagnosis of RD were identified through the procedure-coding database at the Medical Registry of Aarhus University Hospital, which is based on Diagnosis Related Groups (DRG) and used to report to the Danish Patients Registry (LPR). As a University Eye Hospital, we were a natural center for referral of patients with $\mathrm{RD}$ in the region and therefore also likely to receive patients that had previous cataract surgery at our hospital. The electronic list of patients 
with a diagnosis of RD contained about 1251 visits in the 6year period. This list was cross-matched with the list of cataract-operated patients to identify cases with RD after cataract surgery. Furthermore LPR provided a list of all patients from the cohort of cataract surgeries, which at some time had been given the diagnosis of retinal detachment. This could be done because both lists contained the unique CPR-number (civil registry number), which uniquely identifies every citizen in Denmark. Finally, the case record of each case was reviewed to verify the diagnosis and to check for comorbidity or other factors relating to the development of RD. For each case the age of the patient, gender, axial length, surgical complications, postoperative Nd:YAG capsulotomy and time interval between cataract surgery and RD were recorded.

The effect of axial length on the incidence of $\mathrm{RD}$ was evaluated stratifying the population into seven groups in regard to the axial length $(<20,20-22,22-24,24-26,26-28$, $28-30,>30 \mathrm{~mm}$ ) and in each group the number of patients with retinal detachment was compared to the number patients operated for cataract.

From the national register of causes of death a list of eventual death and date of death was obtained for the cohort of cataract surgeries. Kaplan-Meier survival curves were made using Med Calc statistical software. Endpoints were death or RD.

In order to compare the observed incidence with the normal incidence we used the reported incidence of 0.00029 RDs per person year as found by Nørregård [12] in a likewise Scandinavian population. The incidence was survival-corrected according to age and gender related death rate published by Statistics Denmark (www.dst.dk).

For statistical analysis of group means unpaired t-test was applied. For the analysis of contingency tables the Chisquare test was applied.

\section{RESULTS}

The mean follow-up time was 64.8 months (range $26.2-$ 97.6 months). Forty-eight (48) cases of RDs in 48 patients were identified making an overall cumulative risk of $0.39 \%$. The time interval between cataract surgery and RD varied from 0.03 to 77.8 months (mean 26.5 months). The KaplanMeier survival curves are shown in Fig. (1). A significant difference was found between males and females ( 0.0004 . $\log$ rank test).

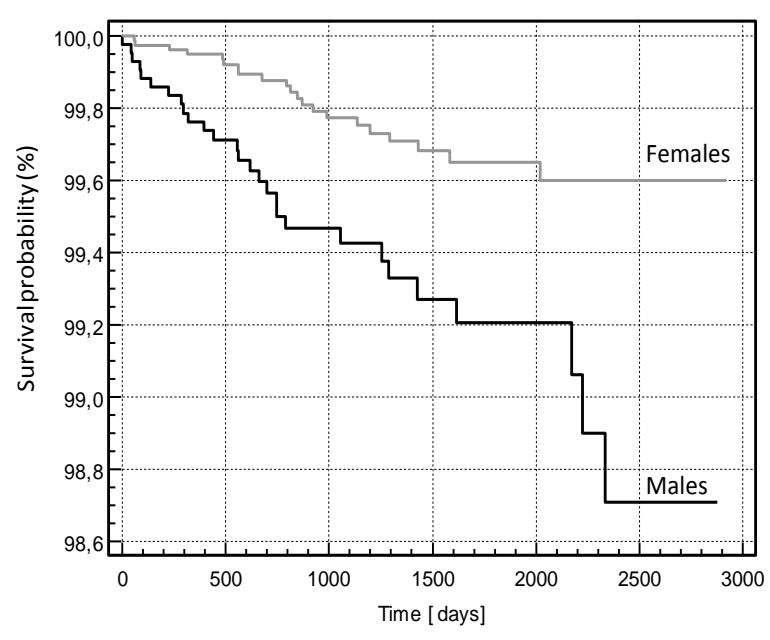

Fig. (1). Kaplan-Meier survival curves for males and females after cataract surgery.

As compared to the normal incidence of $\mathrm{RD}$ reported in the Scandinavian literature [12], the relative risk of RD following cataract surgery was about 2.4 times that of the natural incidence after 52 months.

As compared to the average cataract group, the group of RD following cataract surgery was characterized by a younger mean age (60.5 vs 73.7 years), male gender $(58.3 \%$ vs $34.9 \%$ ), longer axial lengths (24.56 vs $23.25 \mathrm{~mm}$ ) and a higher frequency of surgical complications (10.4\% vs 1.9 $\%)(\mathrm{p}<0.001)$ (Table 1). The complications were capsular tear with vitreous loss in all 5 cases, in one of whom the nucleus was dropped. The male eyes had a mean axial length of $24.96 \mathrm{~mm}$ as compared to $24.04 \mathrm{~mm}$ of the female eyes $(p=0.01)$. No significant difference was found between the incidence of $\mathrm{Nd}$ :YAG capsulotomy cases in the RD group as compared to cases in the normal cataract group (3 $(6.3 \%)$ versus $1159(9.5 \%), p>0.05)$. Seven (7) of the RD cases were found to have a history of previous ocular trauma and 2 cases were diagnosed with subluxation of the lens of unknown cause.

In Fig. (2) is shown the distribution of the axial length in the RD group as compared to the normal cataract population.

When analyzed for the axial length dependency, the incidence of RD was found to increase from its lowest value of $0.18 \%$ in the normal and shorter eyes (axial length $<24$ $\mathrm{mm}$ ) to its highest value of about $2.8 \%$ in the longer eyes (27-28 $\mathrm{mm}$ of axial length) as shown in Fig. (3).

Table 1. Clinical Data of the Group of Retinal Detachment (RD) After Cataract Surgery Compared with the Normal Group of Cataract Operated Patients

\begin{tabular}{|c|c|c|c|c|c|}
\hline & $\mathbf{N}$ & $\begin{array}{l}\text { Age (Years) } \\
\text { Mean } \pm \text { SD } \\
\text { Min - Max }\end{array}$ & Male (\%) & $\begin{array}{c}\text { Axial Length }(\mathbf{m m}) \\
\text { Mean } \pm \text { SD } \\
\text { Min - Max }\end{array}$ & $\begin{array}{c}\text { Complications (n) } \\
(\%)\end{array}$ \\
\hline $\mathrm{RD}$ & 48 & $\begin{array}{c}\left.60.45^{*}\right) \pm 12.5 \\
31-89\end{array}$ & $58.3^{* *}$ & $\begin{array}{l}\left.24.56^{*}\right) \pm 1.76 \\
20.95-29.68\end{array}$ & $\begin{array}{c}\left.5^{* *}\right) \\
10.4 \%\end{array}$ \\
\hline Normal & 12,174 & $\begin{array}{c}73.7 \pm 12.1 \\
21-101\end{array}$ & 34.8 & $\begin{array}{c}23.25 \pm 1.40 \\
18.00-33.64\end{array}$ & $\begin{array}{c}225 \\
1.8 \%\end{array}$ \\
\hline
\end{tabular}

*) RD group different from normal cataract group ( $\mathrm{p}<0.001$ by unpaired t-test).

$* *)$ RD group different from normal cataract group ( $p<0.001$ by chi-square test). 


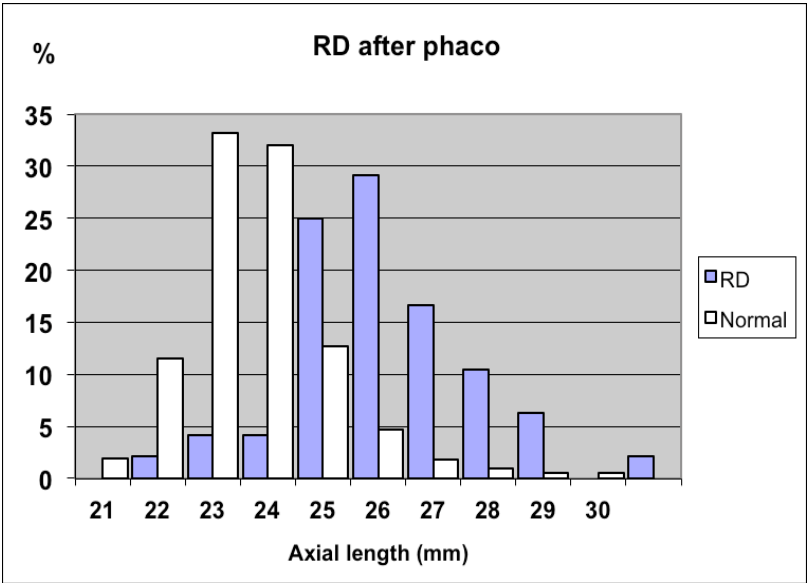

Fig. (2). The distribution of axial length in the group of retinal detachments after cataract surgery (RD) as compared to the group of normal cataract patients.

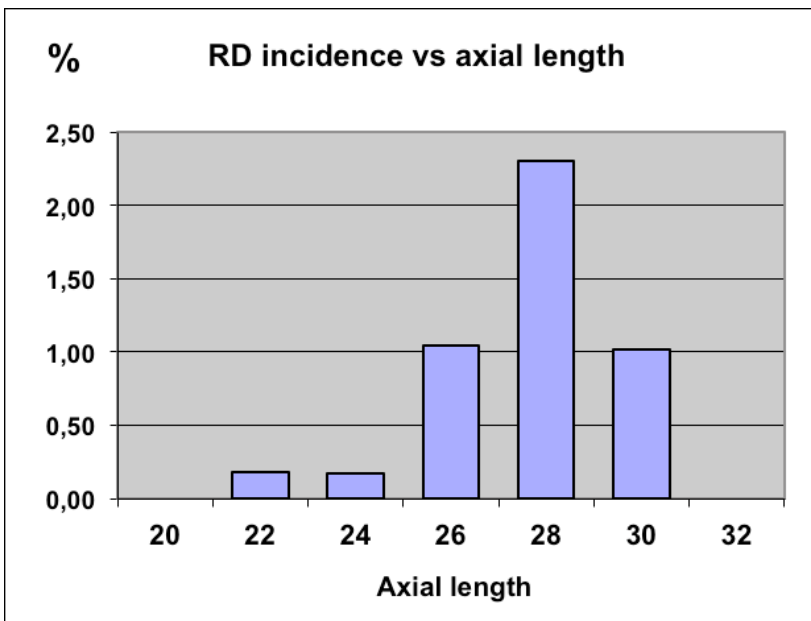

Fig. (3). The incidence of retinal detachment after cataract surgery (RD) as a function of axial length.

When analyzed for the age dependency, the incidence of $\mathrm{RD}$ was found to be highest among the subjects in the fifth decade $(2.1 \%)$ and to decrease in the older age groups (Fig. 4).

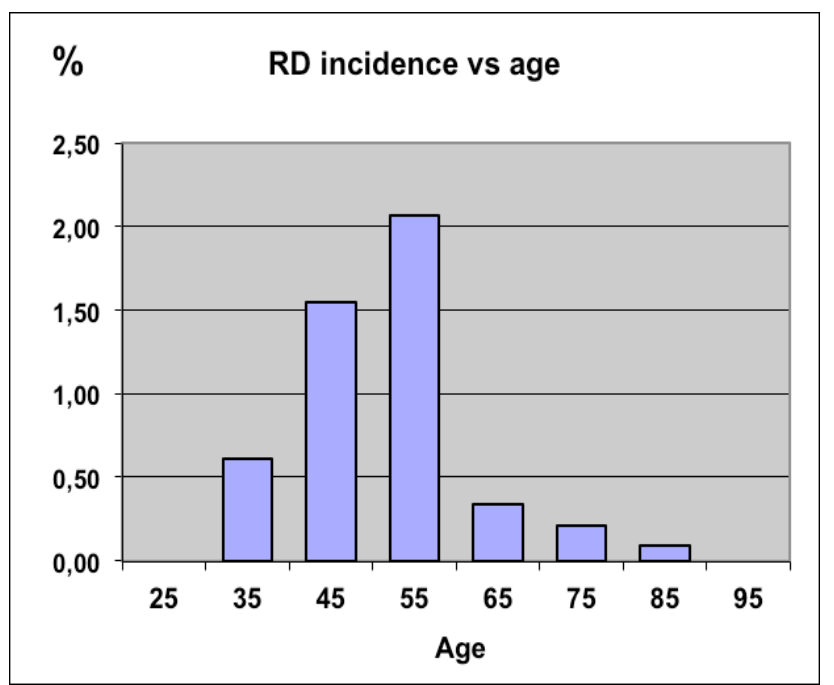

Fig. (4). The incidence of retinal detachment (RD) following cataract surgery as a function of age.

\section{DISCUSSION}

The present study has confirmed that the incidence of RD after cataract surgery is higher than the incidence in a normal cataract population. As compared to previously reported incidence of retinal detachment in a Scandinavian population, the incidence was found to be about 2.4 times higher after cataract surgery. However, our cumulative incidence of $0.39 \%$ after approximately 4 years is among the lowest value reported in the literature.

Javitt et al. in a study of 57105 cases 66 years or older found the cumulative risk to be $0.81 \% 3$ years after surgery [2]. Boberg-Ans et al. in a study of 6352 eyes found the 8year cumulated incidence of RD after phacoemulsification to be $0.93 \%$ per eye or 8.77 times higher than expected [5]. Bhagwandien et al. found in 3921 eyes of 2794 patients an overall cumulative incidence of $0.62 \% 4$ years following cataract surgery [16]. In a 25-year study period Erie et al. found the incidence of $\mathrm{RD}$ in a group of 10256 cataract surgeries to increase in a nearly linear manner showing cumulative probabilities of RD of $0.27 \%, 0.71 \%, 1.23 \%$, $1.58 \%$, and $1.79 \% 1,5,10,15$, and 20 years after cataract surgery, respectively [6].

Clark et al. found in a study of 65055 cases that the fiveyear cumulative incidence nearly was reduced by a factor of 4 between the period of $1989-93$ and $1999-2001$ from $0.96 \%$ to $0.25 \%$ [4]

Numerous studies from different parts of the world have confirmed the risk of $\mathrm{RD}$ to be increased with myopia whether or not the patient is having cataract surgery. In a study from Rome of 930 eyes with high myopia more than $15 \mathrm{D}$ (mean age 62 years) RD was observed in $8 \%$ of cataract extracted eyes as compared to $1.2 \%$ of control eyes [8]. In a study from New Zealand of 141 patients with RD the annual incidence for RD was found to be 11.8 cases per 100.000 people [18]. The incidence was more common after ocular trauma, high myopia and cataract extraction. In a study from Taiwan of 9,398 cataract surgeries RD developed in $0.4 \%$ at a mean follow-up time of 25.5 months [19]. Age and axial length was found to have a significant influence on the incidence. In the study from The Netherlands an overall incidence of $0.62 \%$ was found with increased axial length being a significant risk factor while old age was found to be a protective factor [16]. In the study from Minnesota, USA the cumulative probability ratio of RD remained 4.0-fold higher than controls 20 years after surgery, with increased risk for male gender, younger age and myopia [5] and Clark and et al. found the younger age and male gender significantly increased the risk of retinal detachment [4]. In a study from London of 63,298 cataract extractions axial length greater than $23 \mathrm{~mm}$ resulted in an odds ratio of 3.2 for the development of RD as compared to controls [7]. The latter study was remarkable in the finding of capsule tears to be responsible for $37 \%$ of the RDs after cataract surgery.

Most of the reports have found an increased incidence of RD after surgical complications like capsule tear with vitreous loss. One exception to this rule is a study by Gimbel et al. [20], who observed no cases of RD in a series of 83 eyes with posterior capsule tears from a total of 18470 consecutive cataract surgeries. 
The risk of RD has been reported to be associated with Nd:YAG capsulotomy in some studies [9-11, 15], while other studies have failed to indicate a major increased risk $[7,14,17,21]$. In the present study the incidence of Nd:YAG capsulotomy was found to be less than $10 \%$ in the normal cataract group and was not found to be increased in the $\mathrm{RD}$ group. It is possible that the lower rate of $\mathrm{Nd}: \mathrm{YAG}$ capsulotomy may be one reason for the lower RD incidence found in the present study.

The preponderance of male gender has been noted in many studies. Some of this association may be explained by the fact that male eyes are longer than female eyes in the normal population [22]. Also to be considered is the association with trauma which is likely to occur more frequent in males than in females. In the present series 6 cases (all males) were identified to have had an ocular trauma in their history, possibly increasing the risk of RD.

Perhaps the most striking association with RD found in the present study was the increased risk in the younger patients. The risk of RD was found to around $1.5 \%$ in the fourth decade reaching a peak in fifth decade of more than $2.0 \%$ and to decrease significantly thereafter. For an 80 year old, the risk was below $0.1 \%$ irrespective of the axial length. Recognizing the increased risk of $\mathrm{RD}$ in especially young myopic subjects it seems indicated to perform careful preoperative retinal evaluation of these patients to identify possible retinal tears or other degenerative changes that may need treatment prior to lens surgery, if that is indicated.

\section{ACKNOWLEDGEMENT}

Supported by a grant from Danish Eye Health Society, Copenhagen, Denmark.

\section{CONFLICT OF INTEREST}

The authors confirm that this article content has no conflicts of interest.

\section{REFERENCES}

[1] Javitt JC, Vitale S, Canner JK, Krakauer H, McBean AM, Sommer A. National outcomes of cataract extraction. I. Retinal detachment after inpatient surgery. Ophthalmology 1991; 98: 895-902.

[2] Javitt JC, Street DA, Tielsch JM, et al. National outcomes of cataract extraction. Retinal detachment and endophthalmitis after outpatient cataract surgery. Cataract Patient Outcomes Research Team. Ophthalmology 1994; 101: 100-5.

[3] Lois N, Wong D. Pseudophakic retinal detachment. Surv Ophthalmol 2003; 48: 467-87.

[4] Clark A, Moriet N, Ng J, Preen D, Semmens J. Risk for retinal detachment after phacoemulsification: a whole-population study of cataract surgery outcomes. Arch Ophthalmol 2012;130(7): 882-8.
[5] Boberg-Ans G, Henning V, Villumsen J, la Cour M. Longterm incidence of rhegmatogenous retinal detachment and survival in a defined population undergoing standardized phacoemulsification surgery. Acta Ophthalmol Scand 2006; 84: 613-8.

[6] Erie JC, Raecker MA, Baratz KH, Schleck CD, Burke JP, Robertson D M. Risk of retinal detachment after cataract extraction, 1980-2004: a population-based study. Ophthalmology 2006; 113: 2026-32.

[7] Tuft SJ, Minassian D, Sullivan P. Risk factors for retinal detachment after cataract surgery: a case-control study. Ophthalmology 2006; 113: 650-6.

[8] Ripandelli G, Scassa C, Parisi V, Gazzaniga D, D'Amico DJ, Stirpe M. Cataract surgery as a risk factor for retinal detachment in very highly myopic eyes. Ophthalmology 2003; 110: 2355-61.

[9] Ninn-Pedersen K, Bauer B. Cataract patients in a defined Swedish population, 1986 to 1990 . V. Postoperative retinal detachments. Arch Ophthalmol 1996; 114: 382-6.

[10] Tielsch JM, Legro MW, Cassard SD, et al. Risk factors for retinal detachment after cataract surgery: a population-based case-control study. Ophthalmology 1996; 103: 1537-45.

[11] Koch DD, Liu JF, Gill EP, Parke DW. Axial myopia increases the risk of retinal complications after neodymium-YAG laser posterior capsulotomy. Arch Ophthalmol 1989; 107: 986-90.

[12] Norregaard JC, Thoning H, Andersen TF, Bernth-Petersen P, Javitt JC, Anderson GF. Risk of retinal detachment following cataract extraction: results from the International Cataract Surgery Outcomes Study. Br J Ophthalmol 1996; 80: 689-93.

[13] Naeser K, Baggesen K, Knudsen EB. Retinal detachment following intracapsular cataract extraction: a 10-year follow-up study. Acta Ophthalmol Scand 1998; 76: 727-30.

[14] Olsen G, Olson RJ. Update on a long-term, prospective study of capsulotomy and retinal detachment rates after cataract surgery. J Cataract Refract Surg 2000; 26: 1017-21.

[15] Powell SK, Olson RJ. Incidence of retinal detachment after cataract surgery and neodymium: YAG laser capsulotomy. J Cataract Refract Surg 1995; 21: 132-5.

[16] Bhagwandien AC, Cheng YY, Wolfs RC, van Meurs JC, Luyten GP. Relationship between retinal detachment and biometry in 4262 cataractous eyes. Ophthalmology 2006; 113: 643-9.

[17] Nielsen NE, Naeser K. Epidemiology of retinal detachment following extracapsular cataract extraction: a follow-up study with an analysis of risk factors. J Cataract Refract Surg 1993; 19: 67580.

[18] Polkinghorne PJ, Craig JP. Northern New Zealand rhegmatogenous retinal detachment study: epidemiology and risk factors. Clin Experiment Ophthalmol 2004; 32: 159-63.

[19] Sheu SJ, Ger LP, Chen JF. Risk factors for retinal detachment after cataract surgery in southern Taiwan. J Chin Med Assoc 2005; 68: 321-6.

[20] Gimbel HV, Sun R, Ferensowicz M, Anderson PE, Kamal A Intraoperative management of posterior capsule tears in phacoemulsification and intraocular lens implantation. Ophthalmology 2001; 108: 2186-9.

[21] Jahn CE, Richter J, Jahn AH, Kremer G, Kron M. Pseudophakic retinal detachment after uneventful phacoemulsification and subsequent neodymium: YAG capsulotomy for capsule opacification. J Cataract Refract Surg 2003; 29: 925-9.

[22] Olsen T, Arnarsson A, Sasaki H, Sasaki K, Jonasson F. On the ocular refractive components. The Reykjavik Study. Acta Ophthalmol Scand 2007; 85: 361-6. 